\title{
A System for the Inclusion of the Informal Recycling Sector (IRS) in Mexico City's Solid Waste Management
}

\author{
Francisco Gutiérrez-Galicia ${ }^{1, * \mathbb{C}}$, Ana Lilia Coria-Páez ${ }^{2}$, Ricardo Tejeida-Padilla ${ }^{3}$ (ID and Emma Frida Galicia-Haro ${ }^{2}$ \\ 1 Instituto Politécnico Nacional, UPIIH, Pachuca 42162, Mexico \\ 2 Instituto Politécnico Nacional, ESCA Tepepan, Ciudad de México 16020, Mexico; acoria@ipn.mx (A.L.C.-P.); \\ fgalicia@ipn.mx (E.F.G.-H.) \\ 3 Instituto Politécnico Nacional, EST, Ciudad de México 07630, Mexico; rtejeidap@ipn.mx \\ * Correspondence: fgutierrezga@ipn.mx
}

Citation: Gutiérrez-Galicia, F;

Coria-Páez, A.L.; Tejeida-Padilla, R.; Galicia-Haro, E.F. A System for the Inclusion of the Informal Recycling Sector (IRS) in Mexico City's Solid Waste Management. Sustainability 2021, 13, 12490. https://doi.org/ $10.3390 /$ su132212490

Academic Editor: Munjed A. Maraqa

Received: 18 September 2021

Accepted: 9 November 2021

Published: 12 November 2021

Publisher's Note: MDPI stays neutral with regard to jurisdictional claims in published maps and institutional affiliations.

Copyright: () 2021 by the authors. Licensee MDPI, Basel, Switzerland. This article is an open access article distributed under the terms and conditions of the Creative Commons Attribution (CC BY) license (https:// creativecommons.org/licenses/by/ $4.0 /)$.

\begin{abstract}
With 19 million inhabitants, Mexico City is the most populated agglomeration in Latin America, concentrating $30 \%$ of the national population. More than $61 \%$ of municipal solid waste (MSW) is sent to landfills, and 13\% of MSW is recovered by Informal Sector Recyclers (ISRs) for recycling, which is the most crucial treatment option in the city. This article adopts a systemic approach to addressing the problem of the operationalization of relationships between ISRs and public services in Mexico City to design a recursive organizational structure with the identification of the critical roles and functions of management and governance in multi-level and multi-stakeholder relationships to integrate ISRs into MSW management. Using the Viable System Model (VSM) recursive structure to propose functional organizational structures in Mexico City is a new route for the study and application of systemic thinking in ISR integration. The VSM of the recycling system in Mexico City considers the recycling activities and characteristics of the territory at each recursion level. The authorities of the corresponding hierarchical level, who have sufficient knowledge of the physical and socioeconomic characteristics of the territory, are responsible for the design and operations.
\end{abstract}

Keywords: informal recycling sector; soft system methodology; Mexico City; viable system model (VSM)

\section{Introduction}

Informal Sector Recyclers (ISRs) are individuals or enterprises involved in recycling and waste management activities but who are not sponsored, financed, recognized, or allowed by the formal solid waste authorities or who operate in violation of or competition with proper authorities [1]. It is important to note that the definition of informality in MSW recycling is due to the lack of inclusion in the planning and offering of services by the authorities in charge of waste management.

Globally, it is estimated that there are 20 million people dedicated to recycling waste informally, which represents approximately $50 \%$ of the workers involved in waste management, providing a livelihood to around $0.5 \%$ of urban populations [1]. Recent evidence shows that $20-30 \%$ of recycling rates are achieved by ISR systems, reducing collection and disposal costs $[2,3]$. They play a vital role in the value chain by reprocessing waste into secondary raw materials. In developing countries, informal sector recycling recovers the most significant amount of waste for recycling, and in some cases, this is the only organized form of recycling [4]. However, due to the lack of recognition from local authorities, working conditions in this sector are associated with poverty, exploitation, discrimination, child labor, social rejection, and a lack of education [5].

Waste management systems in megacities represent a critical part of the sustainability agenda, as they are a primary source of pollution in urban areas. Local authorities need to develop programs to contain waste flows, reduce energy and resource consumption, and increase local and global recycling and reuse. Addressing these problems in megacities is 
complex due to the interactions between the hundreds of stakeholders involved in megacity waste management and the lack of initiatives to integrate the informal sector into waste management activities [5].

According to the United Nations (UN), one of the five most populated areas in the world [6] is the metropolitan area of Mexico City, with 20.1 million inhabitants in 2014 [7]. Mexico City comprises 30\% of the country's urban population, in which a large number of work centers, activities, and places of interest are concentrated. Therefore, it is considered the economic and political center of Mexico, which gives the city an accelerated pace of life, which is reflected in the consumption and use of natural resources, with a direct impact on the generation of municipal solid waste (MSW) typical of a megacity [8].

Due to the size of its population and the concentration of economic and cultural activities, Mexico City is among the largest generators of solid waste, with an estimated daily volume of 13,149 tons and a per capita generation of $1.40 \mathrm{Kg} /$ inhabitant*day [9]. The management of MSW is a challenge for the mayors in charge of the collection due to traffic density. According to current environmental regulations, the city government is in charge of the treatment and final disposal of the MSW for the amount generated and the lack of adequate areas within its territory [10]. Three different groups carry out the integral management of the MSW in Mexico City: the public cleaning service that performs the sweeping, collection, transport, and final disposal and treatment; the informal workers that carry out the manual separation of the MSW for recycling; and the private companies in charge of the industrial collection and recycling centers [9].

The staff of the waste collection system consists mainly of three positions: operators (drivers), assistants, and volunteers; the last two are in charge of assisting citizens in emptying their waste into the truck for transport. Their pay differs as the volunteers do not receive a salary from the mayor's office but rely on their tips and the sale of valuable materials [9]. It is estimated that Mexico City has around 3834 informal workers [11], and the recyclable materials extracted by them represent approximately $12.6 \%$ of the overall waste generated, nearly 1700 ton per day [9]; this percentage shows us the area of opportunity that Mexico City has for waste management and environmental culture regarding in-home waste separation, considering that $27.18 \%$ of MSWs are recyclable [12].

There is evidence in developing countries in South America, Asia, and Africa that, despite the difficulty of incorporating IRS into a city's MSW management system, its achievement represents benefits for all sectors involved [13], using three different approaches [14].

The most widely used approach considers the organization of the IRS into associations and cooperatives. In this model, local authorities and workers organize themselves into associations or cooperatives to establish agreements to provide waste collection and recycling services [2,14-16]. For the most part, their income is not fixed but is highly dependent on the quantity and quality of recyclable materials collected and sold on the local recycling market. To this end, Brazil and India have included in the national policies on solid waste management that informal recyclers should be recognized as important actors in the MSWM system, highlighting the need to include recycling associations and cooperatives in collection and recycling programs $[17,18]$. However, in Colombia, the participation of the IRS promotes bidding processes for services related to the management of MSW [19].

Another approach is the organization of waste pickers in community-based organizations (CBOs) or micro and small enterprises (MYEs). COBs are formed when individuals provide waste services in their marginalized communities on the periphery of urban areas lacking basic sanitation services, such as waste management. For some of its members, this situation represents an opportunity to receive income for waste collection and recycling services, such creating a clean environment for themselves and their community [14]. In this approach, the municipality plays a minor role, supporting regulations, equipment and infrastructure, and awareness activities. The income of formalized waste workers is covered mainly by waste collection fees (paid by users) and, in recycling cases, with the 
sale of recycled materials [20]. In Peru, waste regulations support the formalization of informal recyclers, which indicates that local governments support the creation of associations, cooperatives, MPEs, and those included in separate public collection and recycling programs [14]. In Kingston, Jamaica, informal recyclers working in OCB activities are encouraged to participate in the National Solid Waste Management Reorganization Plan, which aims to improve their economic and health security [21].

The traditional approach to including ISRs is adopting informal waste workers as workers for the formal waste management sector. By carrying out certain activities, they already have experience and do not require specialized equipment, such as manual sweeping or separation in recycling facilities. In this case, incorporating informal waste pickers helps to alleviate poverty, since people who occupy these positions are often poor. This objective tends to ignore the importance of informal recyclers in recycling waste and attempts to improve their performance without addressing the social and political factors that influence it [22].

However, there are no previous experiences of incorporating the IRS into a megacity such as Mexico City, in which MSW management is a complex system due to the local and regional waste streams that converge into it and the differences involved in waste management: service providers and formal and informal authorities, between which countless interactions are established [23].

This work raises a research question: How can the IRS be incorporated into a complex MSW management system such as that of Mexico City to improve living conditions and increase recyclable waste recovery? A systems science approach is proposed to cover all aspects and variables of the problematic situation using the Viable Model System (VSM) [13,23].

\section{Materials and Methods}

\subsection{Case Study}

According to the National Census of Municipal and Delegation Governments, Mexico City is the urban area that generates the most waste. It has the highest per capita generation rate [24]; for the year 2019, it was estimated that 13,149 tons/day were generated, with a per capita generation of $1.40 \mathrm{~kg} /$ inhabitants * day in Mexico City [9].

According to the latest study at transfer stations made in 2008, 27.18\% of MSWs are recyclable, $49.95 \%$ are organic, and only $22.87 \%$ of waste is not suitable for recovery or able to undergo organic treatment [12]. As there are limited recent data on the composition of MSW, it is considered that this has remained constant [12].

\subsubsection{Solid Waste Management in Mexico City}

The use of the Process Flow Diagram (PFD) to represent a city's solid waste and recycling system, including formal and informal elements and operations, is highly recommended. As previously demonstrated, a PFD is a relatively robust way of presenting the system as a whole in a comprehensive but concise way [5].

Figure 1 shows the process flow diagram (PFD) of solid waste management in Mexico City, the relationships, and the stakeholder group of each process. Local legislation indicates that the inhabitants have to divide MSW into two fractions: organic and inorganic. 


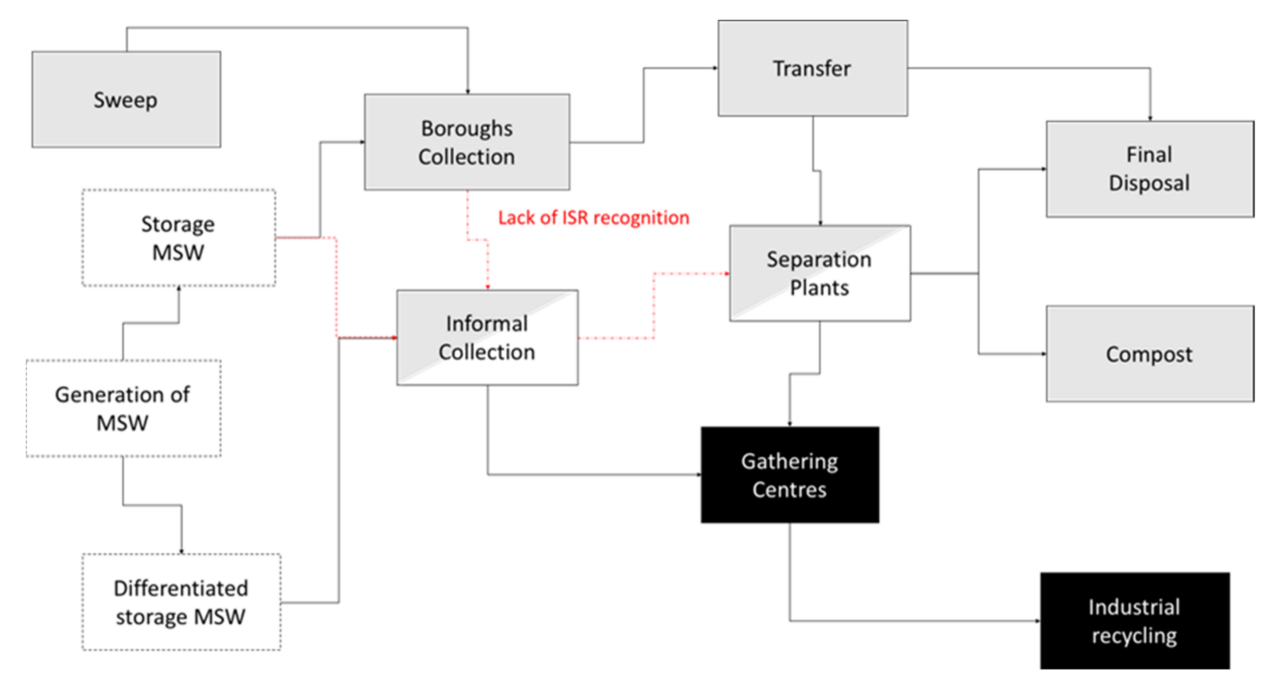

Figure 1. Municipal solid waste management (MSWM) in Mexico City [10].

The squares in dotted lines in Figure 1 indicate the activities carried out by the inhabitants. Since the separation of all MSWs has not yet been achieved, a part of them is collected mixed; it is shown in the figure that there are two different types of storage, mixed and buried [10]. In Mexico City, there are 1888 colonies or towns distributed in the 16 municipalities that make up the city, and each of them is served by a collection route. The municipalities operate and coordinate the MSW collection routes within their territory and the informal recycling sector.

Public services are indicated in grey rectangles. Each of the 16 municipalities collects and sweeps the MSW within its territory to deposit it into 1 of the 12 transfer stations operated by the city government. Organic waste, such as food and gardening waste, from the transfer stations is sent to a composting plant. Regarding inorganic waste, $78 \%$ is sent to final disposal in landfills outside Mexico City [9]. The remaining 22\% of inorganic waste is sent to separation plants to recover waste of economic value, such as PET, cardboard, paper, metals, and glass for recycling, and the remainder is sent to landfills [9].

The lack of ISR recognition means that for them to carry out MSW recycling activities, it is necessary to voluntarily join the public service to collaborate in the activities of the cleaning services. ISRs (waste-pickers, voluntary helpers, and recycling traders) pick out recyclables, process them, and sell them (through a chain of intermediaries) to the recycling industry (cardboard, bottles, iron, paper, and metal). All collected waste is segregated into bundles, sacks, and bags to be sold at any gathering center [25]. In specific neighborhoods, informal waste handlers outweigh municipal employees [26]. A part of the collected waste is sent to separation plants, where waste pickers who lived in the rubbish dumps that existed in the city before landfills are used to separate the MSW manually. The wastes they recycle are those that have economic value. Therefore, the rectangles related to the collection and separation plants are gray and white, respectively, since both public services and ISRs intervene.

One of the main problems of MSW collection in Mexico City is its efficiency. Due to volunteers' presence, currently, collection vehicles are operated by more workers than are required. In 2018, there were two grassroots and two informal workers on each route, collecting an average of 4.46 tons per day (considering that a crew covers a course in one day), which represents only $59 \%$ of the capacity of a collection vehicle with compaction of $15 \mathrm{~m}^{3}$ in good condition, considering that the MSW in the collection vehicles can reach a density of up to $500 \mathrm{~kg} / \mathrm{m}^{3}$ [27]. While in cities such as Tijuana, Ciudad Juárez, and Reynosa, 13.33, 11.57, and 9.78 tons per day per vehicle were reached, respectively, in these cities, the collection service is performed by private companies, who do not allow "pepena" (waste-picking) and maintain collection vehicles with crews made up of three workers [28]. Therefore, waste selection and recovery activities are the main factors that cause low 
collection efficiency in Mexico City. The same occurs in separation plants, where only $5 \%$ of materials are recovered as the work is carried out manually, and the ISR previously selects the MSW during collection.

The services that are in charge are private companies are identified with black rectangles. Private companies focus mainly on the commercialization of recyclable waste on a large-medium scale, so they are the ones that operate the collection centers in which MSWs are classified by type and conditioned for later distribution to companies that carry out the industrial recycling of materials such as steel and glass, inside and outside the country [26].

\subsubsection{Materials and Value Chain Interface in Mexico City}

In Mexico City, the waste with a stable market linked to the recycling chain are paper, cardboard, PET, glass, and metal [29].

In Mexico, paper and cardboard are recoverable waste with an attractive economic value. The domestic paper industry has invested over USD 1 billion to develop a market for secondary fibers, recovering from 355,000 tons in 1970 to 3.2 million tons in 2010 [30]. The Mexican demand for bottled water and soft drinks has grown significantly; over 6000 million gallons of drinks are sold each year. A few decades ago, glass bottles were predominantly used; currently, PET is the most common material used for this purpose (Romero-Hernández et al., 2009), and the increased commodity market resale has made the recycling of PET in Mexico highly lucrative. The price of used PET bottles increased from MXN 0.70/ kg in 2004 to MXN 4.50/ kg in 2010. However, the price paid to PET waste pickers is MXN $2.50 / \mathrm{kg}$ on average (Schwanse, 2011). Aluminum can recycling rates are also driven by industrial demand for the material rather than environmental concern, given that these wastes are scavenged from streets mostly by pickers due to economic necessity. Therefore, even in the absence of recycling programs and environmental regulations, a high recycling rate would occur if the price paid for the material was a sufficient incentive for people to gather it [29]. As these are the waste markets in Mexico City, one ton of recyclable waste has an average value of MXN 2483, considering both the MSW composition and the price of the different materials in 2020, as shown in Appendix A.

ISRs are the first actors to value recyclable materials by separating them from MSWs in collection vehicles or recovering them from homes when inhabitants carry out separation. Therefore, the IRS handles small amounts of waste, which is obtained from homes and small businesses that place their everyday waste at established collection points throughout the day for them to be collected by the collection services that run daily through the many streets of the city. At the end of the day, the ISR delivers the recyclables to collection centers.

Collection centers are small recycling companies that act as critical intermediaries between recyclers and the recycling industry, as the ISR requires the daily commercialization of recyclable waste since it is its only source of income. The collection centers are located near main streets of commercial use to facilitate the access of collection vehicles. Therefore, recycling centers are well located within urban areas, where the land is costly and small. Consequently, collection centers are limited to the amount of recyclable waste they can store in their premises; they can store the bulkiest waste (PET and pallet cardboard) for a few days to a week and less bulky waste (such as metals) for up to a few months, unlike the ISRs, who have to sell what they collect daily. They use machinery adapted to the size of the land and their storage capacity, such as cardboard compactors to make bales of the appropriate weight and volume (between 100 and 600 kilos) to be transported in small vans (larger trailers cannot maneuver in the streets of small neighborhoods) $[8,26]$. Similar to the IRS, collection centers also rely on intermediaries to sell their waste. In addition to reaching the recycling industry, recoverable waste must go through multiple recycling centers of increasing size, each playing a role in the processing and transporting of recyclable waste to recycling facilities.

Industrial recycling centers provide services with machinery suitable for receiving recyclables of hundreds of kilos: their scales, forklifts, and trailers are adapted to these quantities. They are located in industrial zones on the city's outskirts outside urban areas 
with easy access for their suppliers $[8,26]$. Ultimately, recycling centers sell the recyclable waste to transnational companies operating throughout Mexico (for cardboard and metals) or abroad (for plastics) that perform industrial recycling processes to obtain raw materials from the waste to manufacture new products.

Due to the large amount of waste generated in Mexico City, for local authorities, it has been a constant concern to increase the amount of waste that is recycled. In 2003, the Waste Law of the Federal District (now Mexico City) was established to divide separation into two fractions (waste and organic) [31]. Subsequently, in 2017, the NADF-024-AMBT-2013 Standard came into force, whose objective was the separation of waste into four waste fractions (organic, non-recyclable inorganic, recyclable inorganic, and bulky waste) to increase recyclable material separation in homes, and therefore, reduce the waste that is sent to landfills [32]. However, the implementation of the NADF-024-AMBT-2013 standard has not had the expected results, since the separation efficiency decreased from $75 \%$ in 2012 to $55 \%$ in 2019 , and other alternatives are currently being analyzed, such as the creation of cooperatives and microenterprises oriented to the management and recycling of waste [33].

\subsubsection{Social Interface}

Mexico City has an interconnected hybrid system of waste management that has an impact on the institutional arrangements that shape the governance of waste: informality creates opacity, of which local authorities take advantage to determine who and what is politically influential and to enhance their power through prohibition or inclusion strategies [34].

Informality was conceived as a transitional mechanism or a temporary agreement, and local authorities use and allow informal practices, as they consider it impossible to implement a waste policy under local conditions of scarcity. Nonetheless, they recognize their immediate benefits and contributions to formal waste management [34].

\subsection{Viable System Model}

The systems science approach is characterized by considering that the declining complexity, diversity, and changes of systems are due to the growth of operations (in the case of waste collection, final disposal, or treatment); managers finding solutions to problems; and participants-those with interest in the problematic situation (the authorities, informal sector, and population) [23].

The methodology applies the VSM in organizations of different sizes in public and private sectors as a design instrument for a company that is in the process of establishing itself or undergoing a change in identity, as described below [35].

The first stage is to establish the identity of the organization. An identity statement expresses the significance the organization has for its members. From a particular point of view, it is considered a concise but highly descriptive statement of the organization as a total system.

The second stage is the modeling of structural activities, which requires a series of strategic considerations, such as relationships with suppliers and customers, geographical coverage, technological processes, and time. Structural modeling aims to examine the complexity of the organization as a whole, which is central to its strategy and mode of operation [36].

The third stage is the deployment of complexity and modeling of structural levels. To this end, autonomous, emergent, or constituted units are defined as "primary activities"; in addition, a primary activity may have subactivity divisions, and these divisions may have strategic business units until the organization's products or services are delivered [37].

The fourth stage is the modeling of functionality and the organizational structure. Modeling functionality is related to the resources and functions within each primary activity. This is defined as CATWOE, which consists of 6 elements [38]:

- Costumers: the beneficiaries or victims of the transformation process;

- Actors: those who carry out the transformation processes; 
- Transformation: the conversion of inputs and outputs;

- Weltanschauung: vision of the world that makes transformation relevant;

- Owners: those who can prevent the transformation;

- Environment: elements outside the system that restrict inputs and outputs.

Figure 2 shows the construction of a viable model from a system or organization of interest presented in synthetic form [39]. On the left side of the figure, the circle represents an organization, with its management (rectangle), nested in a specific environment (amoeba shape). The center of the figure shows the components of the organization separated to identify their relationships. The arrows represent the management and regulation of the entry and output flow between these elements; the right side of the figure shows the same elements with the components contained in each. The organization contains the common systems, Systems 1, 2, 3, and System 3*, and the management of this organization contains Systems 3, 4, and 5; their definitions are provided in Table 1.

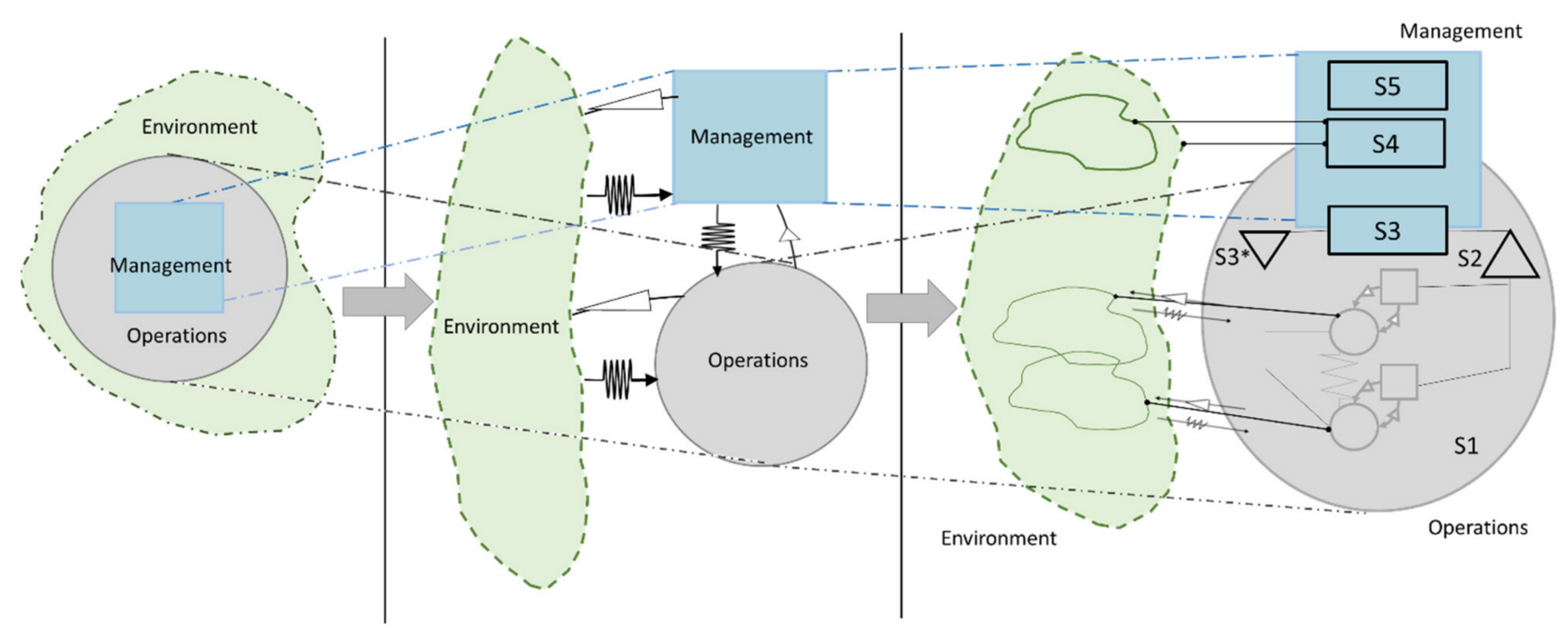

Figure 2. Viable system mode. Source. Based on Perez-Rios [39]. (Adapted with permission from ref. [39]. 2021 Emerald Publishing Limited).

Table 1. Viable system model (VSM) components.

\begin{tabular}{cc}
\hline System 1 & Definition \\
S1 & $\begin{array}{c}\text { This function defines the organization. The primary activities are reflected-those that } \\
\text { constitute the reason for the organization's existence-giving it purpose and defining } \\
\text { its identity. }\end{array}$ \\
S2 & $\begin{array}{c}\text { This function allows languages and protocols of communication between primary activities of } \\
\text { the same recursive level to take care of the consolidation and cohesion of the system in the } \\
\text { execution of its tasks. }\end{array}$ \\
S3 & $\begin{array}{c}\text { This function, often called "the inside and the now", requires a precise appreciation of the } \\
\text { achievements and capabilities of S1 and the coordination of potentialities and requirements to } \\
\text { respect and enable the autonomy of primary activities to establish communication between S3 } \\
\text { and 4. }\end{array}$ \\
S3* & $\begin{array}{c}\text { This function corresponds to intermittent monitoring, which ensures the desired behavior of } \\
\text { the primary activities. }\end{array}$ \\
S4 & $\begin{array}{c}\text { This function is known as "intelligence" and is concerned with the organization's environment } \\
\text { and its prospective and future development (opportunities and threats), facilitating } \\
\text { its adaptation. }\end{array}$ \\
\hline S5 & $\begin{array}{c}\text { This function, known as "politics", is normative and responsible for closing the viable system, } \\
\text { taking care of the integrity and organizational identity of the system. }\end{array}$ \\
\hline Source: Based on Beer [37] and Nuñez et al. [40].
\end{tabular}




\section{Results}

3.1. Identity

For the inclusion of the IRS in MSW management in Mexico City, the development of an organization in which the IRS is responsible for the recycling of waste is proposed so that, through the commercialization of these materials, pickers can earn a decent livelihood. To this aim, local authorities (mayors and city governments) must coordinate the IRS with the public and private services with which they jointly manage the MSW in the city. In addition, the assembly of Mexico City must implement legislation to recognize and regulate the activities carried out by the informal sector to define and maintain its function within the management of MSW in the city.

\subsection{Structural Activities}

To carry out MSW recycling in Mexico City, the required structural activities are the small- and medium-scale separation, storage, collection, and commercialization of recyclable waste. The separation and storage of waste are implemented in the city through the NADF-024-AMBT-2013. This standard indicates that MSW must be separated and stored in four fractions (organic, non-reciprocal, recyclable, and bulky or pots). Each of these fractions has a different destination for the treatment or use of waste according to their characteristics. Thus, the collection and delivery of recyclable waste to collection centers distributed throughout the city near collection areas would be the responsibility of the informal sector. Commercialization would be in charge of the private sector through the collection centers that condition the waste by compaction or cleaning for sale to industrial recycling centers inside and outside the country.

\subsection{Unfolding Complexity}

This section describes the different levels of structural activities. In this case, the first activity for recycling waste is separation and storage, carried out in 2.8 million homes in Mexico City, which are grouped into more than 1800 neighborhoods [9,41]. The collection is carried out twice a week in the case of recyclables, and there is a collection route for each neighborhood [9]. The last activity of recycling MSW in the city is commercialization, which is carried out when the collected recyclables are sold in one of the 23 collection centers distributed in the city, which are later sold in bulk to industrial recycling companies outside the city.

The informal recycling system of Mexico City is displayed in Figure 3, which shows the hierarchical relationships among the primary activities carried out by the administrative, political division.

\subsection{Modeling}

\subsubsection{Modeling Productive Unit}

The entire waste management system's basis is the "productive unit", which should ideally be constituted by the houses or businesses where MSWs are generated. In homes or businesses, MSWs must be classified according to the provisions of the NADF-024-AMBT2013 standard, according to which, inorganic wastes with recycling potential are those that, due to their characteristics, have the technical, economic, and environmental capability of being reincorporated. For processing and treatment, to allow the recovery of paper and cardboard, plastic, metals, glass, clothing, textiles, wood, or multilayer containers, each type of waste is stored separately from the rest of the waste to avoid being contaminated and must be delivered by a generator to the informal recycling sector; the rest of the RSU is delivered by cleaning services. [32]. The components that interact in recursion level 3 (productive unit) are defined in Table 2. 


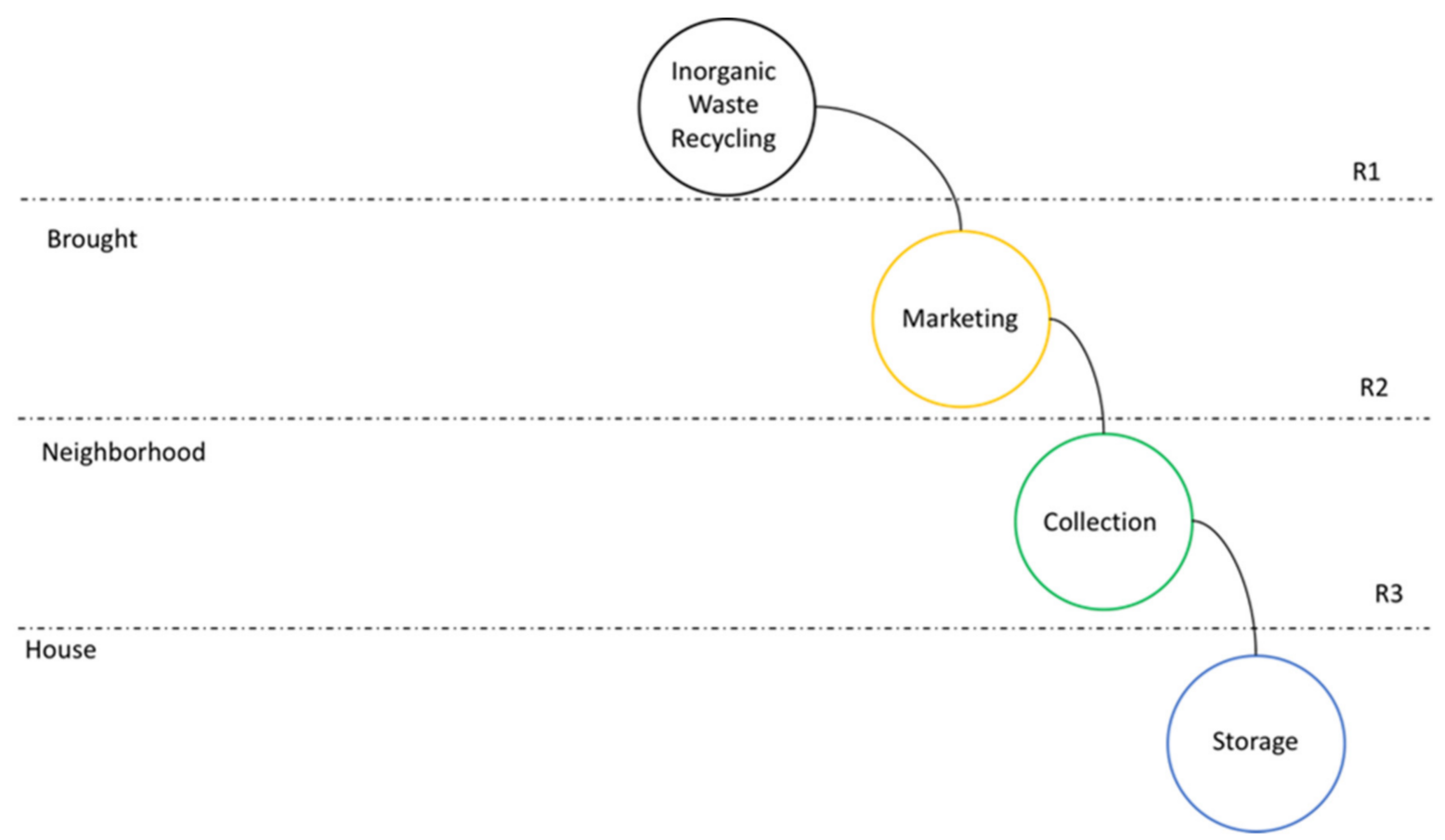

Figure 3. Unfolding complexity of inorganic MSW recycling.

Table 2. Productive unit customers, actors, transformation, weltanschauung, and environment (CATWOE).

\begin{tabular}{|c|c|}
\hline Element & Definition \\
\hline Customers & ISR that collects recyclable MSW. \\
\hline Actors & $\begin{array}{c}\text { The city population, Informal Sector Recyclers (ISRs), cleaning services, } \\
\text { and environmental authorities. }\end{array}$ \\
\hline Transformation & Storage and classification of recyclable waste. \\
\hline Weltanschauung & $\begin{array}{l}\text { One of the main problems in urban areas is the waste generation, so } \\
\text { separation at the source is necessary to recycle as much waste as possible }\end{array}$ \\
\hline Owners & City Environmental Authorities Regulating MSW Classification. \\
\hline Environment & $\begin{array}{c}\text { Consumption habits of Mexico City inhabitants and the regulations } \\
\text { regarding the separation of waste. }\end{array}$ \\
\hline
\end{tabular}

Based on the elements of Table 2, the design of the productive unit level (houses) is proposed in Figure 4.

The interactions between the components of the basic productive unit (neighborhoods) are explained in Table 3. 


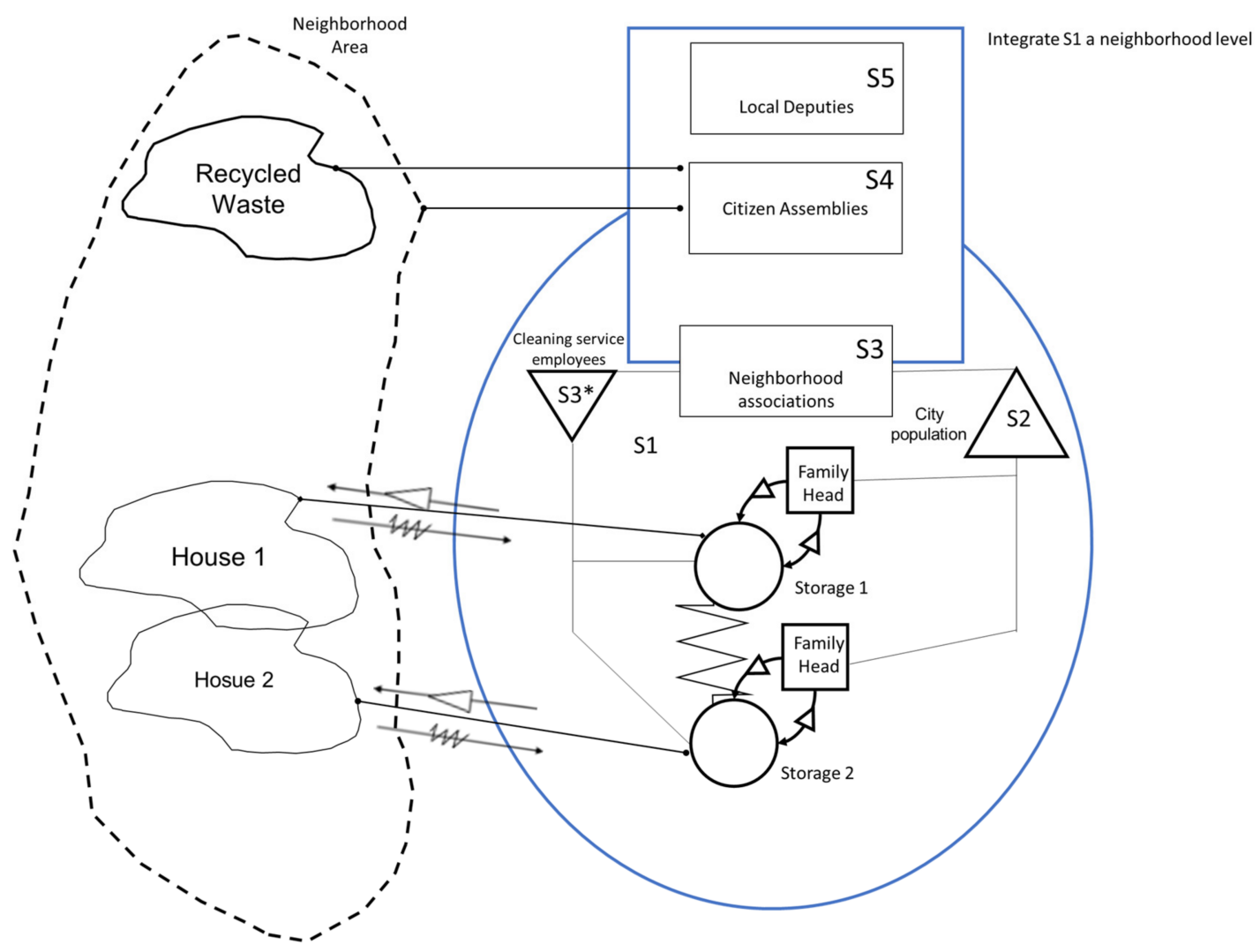

Figure 4. Viable system model of a core productive unit.

Table 3. Productive unit VSM systems and their roles and functions.

\begin{tabular}{cc}
\hline System & Definition \\
\hline $\begin{array}{c}\text { S1-Recycling } \\
\text { Information and } \\
\text { coordination }\end{array}$ & $\begin{array}{c}\text { Differentiated recyclable MSW. } \\
\text { The head of the family is the determining factor for separating the MSW in } \\
\text { the house. }\end{array}$ \\
$\begin{array}{c}\text { S3-Productive } \\
\text { Unit (PU) } \\
\text { Management }\end{array}$ & $\begin{array}{c}\text { Neighborhood associations regulate the types of storage, schedules, and } \\
\text { locations for their proper collection. }\end{array}$ \\
$\begin{array}{c}\text { S3*-PU } \\
\text { Monitoring }\end{array}$ & Collection service workers that verify the efficiency in the classification of \\
the MSW.
\end{tabular}

\subsubsection{Modeling Neighborhood}

In Mexico City, each neighborhood has an MSW collection route responsible for collecting all types of waste and subsequently taking them to a transfer station, and from there to the different kinds of treatment or final disposal plants. To collect recyclable waste, the ISR would be divided into groups of six volunteer workers in a vehicle with a load capacity of fewer than 5 tons without compaction equipment. The ISR requires 630 teams to serve the 1888 neighborhoods of the city twice a week, and each crew attends 3 communities. It is estimated that each of the informal collection crews could generate an income of up to MXN 10,578 per day, considering that a ton of recyclable waste can be marketed at MXN 2483.10, as shown in Table A1 of Appendix A, which would cover 
the cost of operation and replacement of vehicles, uniforms, and PPE. Table 4 outlines the components that should be considered at the neighborhood level.

Table 4. Neighborhood customers, actors, transformation, weltanschauung, and environment (CATWOE).

\begin{tabular}{cr}
\hline \multicolumn{1}{c}{ Element } & Definition \\
\hline Customers & Gathering center. \\
\hline Actors & House, ISR, cleaning services, and collection centers. \\
\hline Transformation & Collection of waste classified as recyclable. \\
\hline Weltanschaung & $\begin{array}{r}\text { The collection of recyclable waste is a job opportunity for the most } \\
\text { vulnerable sectors that cannot obtain formal employment due to their lack } \\
\text { of education. }\end{array}$ \\
\hline Owners & The lack of waste separation at the source contaminates the recyclable \\
Environment & materials and decreases their quantity and value. \\
\hline Source: based on Checkland [38].
\end{tabular}

Based on the elements of Table 4, the design of the neighborhood level is proposed in Figure 5.

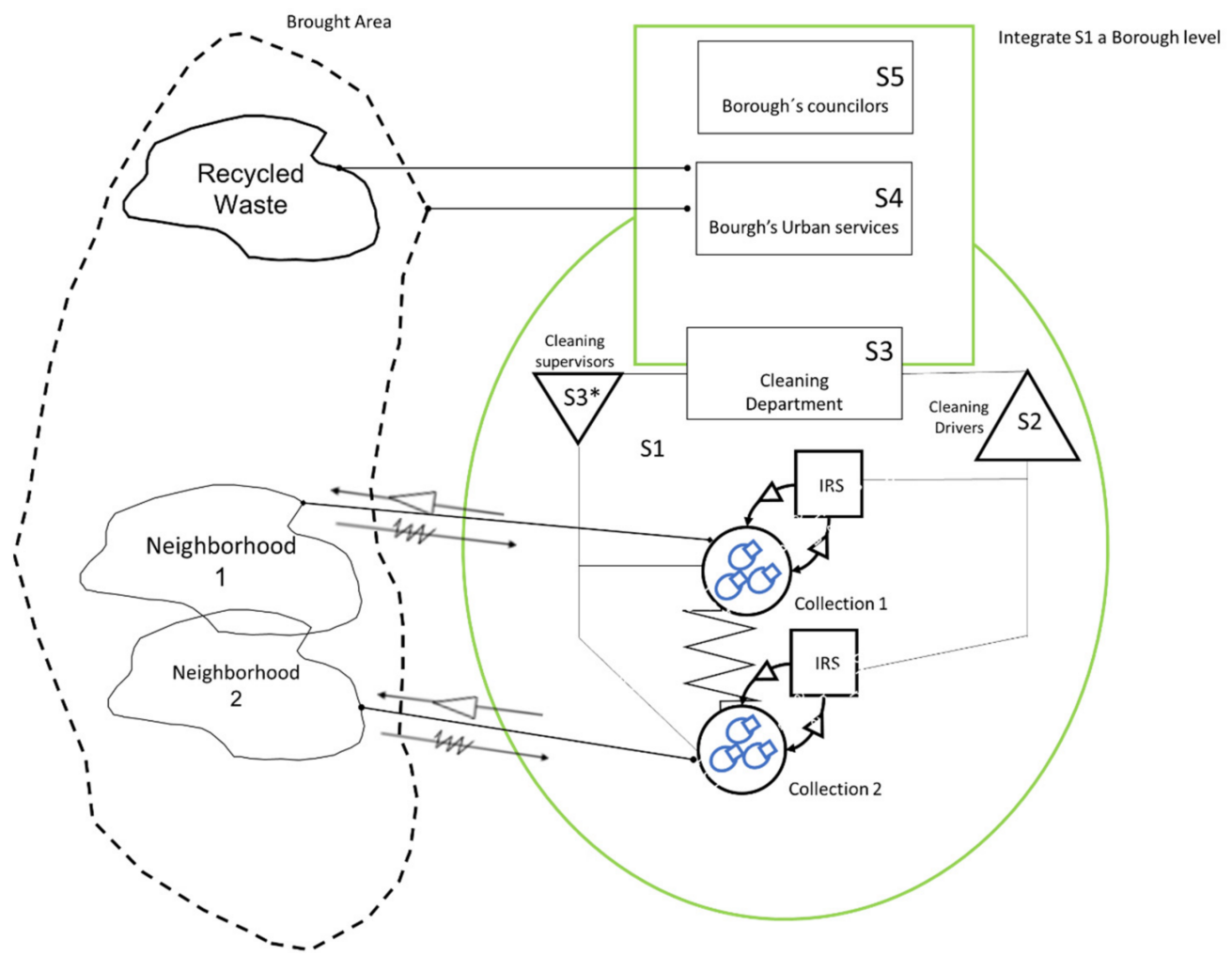

Figure 5. Viable system model of a neighborhood.

In Table 5, the Viable System Model elements related to neighborhood-level recursion are described. 
Table 5. Neighborhood VSM systems and their roles and functions.

\begin{tabular}{cc}
\hline Scheme 1 & Definition \\
\hline $\begin{array}{c}\text { S1-Recycling } \\
\text { Information and } \\
\text { Coordination Unit }\end{array}$ & $\begin{array}{c}\text { Recyclable waste collection by the ISR. } \\
\text { The cleaning service collection routes and the ISR cover the } \\
\text { assigned route without interfering with other courses. }\end{array}$ \\
\hline $\begin{array}{c}\text { S3-Neighborhood } \\
\text { Management }\end{array}$ & $\begin{array}{c}\text { Departmental cleaning and collection units of the municipalities } \\
\text { that design the ISR collection routes and the cleaning services. }\end{array}$ \\
\hline $\begin{array}{c}\text { S3*-Neighborhood } \\
\text { Monitoring }\end{array}$ & $\begin{array}{c}\text { Cleaning supervisors of the municipalities verify that the } \\
\text { collection routes are covered in their entirety. }\end{array}$ \\
\hline Seighborhood Planning & $\begin{array}{c}\text { The borough's urban services establish programs for the } \\
\text { provision of the public cleaning services according to local } \\
\text { regulations and the needs of the population. }\end{array}$ \\
\hline Neighborhood Board & $\begin{array}{c}\text { The borough's councilors represent the population, who, together } \\
\text { with the local borough authorities, propose and approve projects } \\
\text { to improve MSW management. }\end{array}$ \\
\hline
\end{tabular}

\subsubsection{Borough}

Regarding waste recycling facilities, the informal sector's materials are sold in the 23 collection and storage centers distributed throughout the city to decrease transportation costs and recover as much recyclable waste as possible. These small centers are registered with the city government to report the annual amount of waste recycled. The city government has the faculty to promote and regulate the commercialization of materials in centers and the two separation plants [9]. Table 6 outlines the components that should be considered at the borough level.

Table 6. Borough customers, actors, transformation, weltanschauung, and environment (CATWOE).

\begin{tabular}{|c|c|}
\hline Element & Definition \\
\hline Customers & $\begin{array}{l}\text { Recycling centers buy wholesale recyclable waste from collection centers to } \\
\text { be compacted or crushed and sold in bulk for industrial recycling within or } \\
\text { outside the country. }\end{array}$ \\
\hline Actors & $\begin{array}{l}\text { Collection centers, informal recycling sectors, collection centers, and } \\
\text { industrial recycling. }\end{array}$ \\
\hline Transformation & $\begin{array}{c}\text { Marketing of recyclable waste, such as cardboard, paper, beverage } \\
\text { containers, metals, and glass. }\end{array}$ \\
\hline Weltanschauung & $\begin{array}{l}\text { Industrial recycling of waste contributes to sustainable development by } \\
\text { reducing the exploitation of natural resources in the production of new } \\
\text { products. }\end{array}$ \\
\hline Owners & $\begin{array}{l}\text { Collection centers buy the waste that the informal sector recovers on a } \\
\text { small scale according to the market demand for materials. }\end{array}$ \\
\hline Environment & $\begin{array}{c}\text { Commodity market conditions and regulations regarding the manufacture } \\
\text { of products with recycled materials. }\end{array}$ \\
\hline
\end{tabular}

Based on the elements of Table 6, the design of the borough level is proposed in Figure 6. 


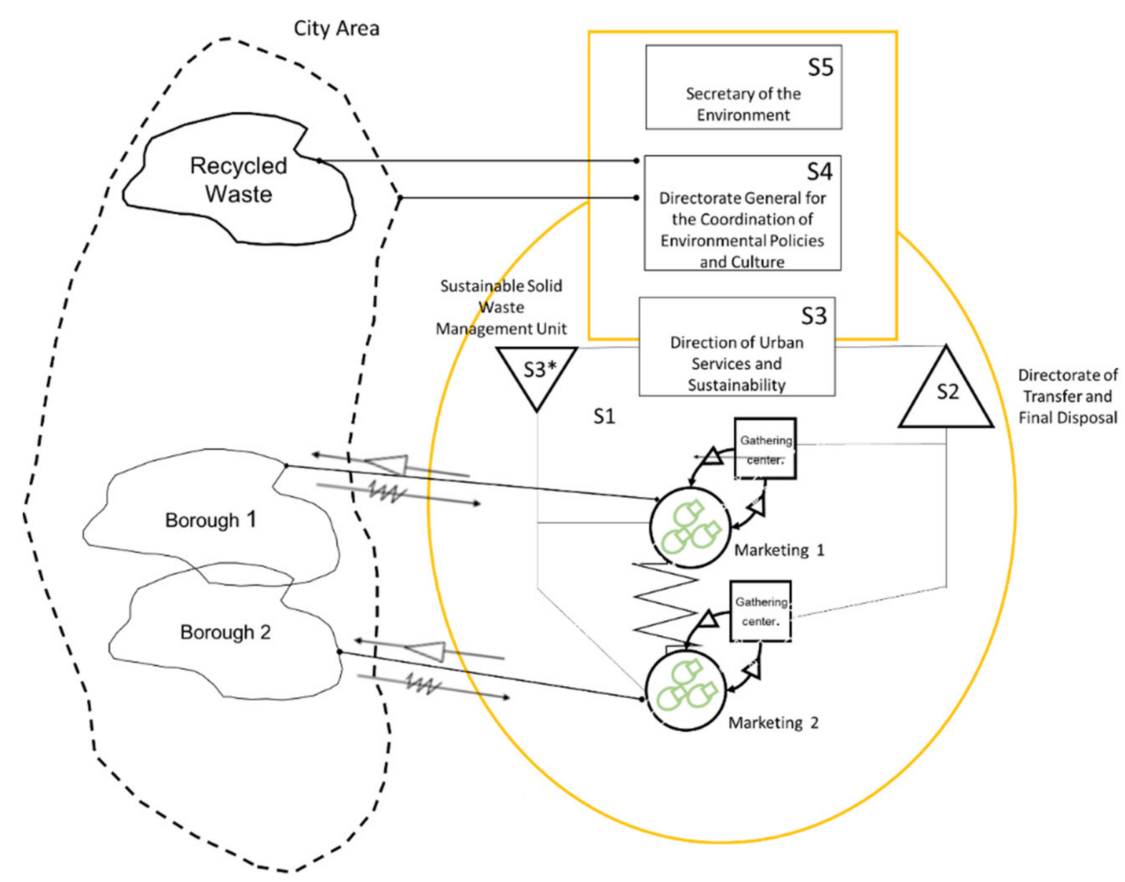

Figure 6. Viable system model of the borough level.

In Table 7, the Viable System Model elements related to borough-level recursion are described.

Table 7. City VSM systems and their roles and functions.

\begin{tabular}{|c|c|}
\hline System & Definition \\
\hline S1-Recycling & Gathering center \\
\hline $\begin{array}{l}\text { S2-Borough and } \\
\text { Coordination Unit }\end{array}$ & $\begin{array}{l}\text { The Executive Directorate of Transfer and Final Disposal of MSW is } \\
\text { responsible for executing the actions related to the integral management of } \\
\text { MSW, based on the Solid Waste Law of Mexico City and its regulations. }\end{array}$ \\
\hline $\begin{array}{l}\text { S3-Borough } \\
\text { Management }\end{array}$ & $\begin{array}{l}\text { The General Directorate of Urban Services and Sustainability establishes } \\
\text { the criteria and technical standards for the global management of MSW; } \\
\text { carries out studies, projects, construction, conservation, and the } \\
\text { maintenance of infrastructure works for the MIR MSW, as well as } \\
\text { organizing and implementing the management, treatment, and final } \\
\text { disposal of MSW; and operates technology for the treatment of MSW. To } \\
\text { this aim, the allocation of financial and personal resources is carried out by } \\
\text { preparing the Annual Operational Program. }\end{array}$ \\
\hline $\begin{array}{l}\text { S3*_City } \\
\text { Monitoring }\end{array}$ & $\begin{array}{c}\text { The sustainable solid waste management unit is in charge of monitoring } \\
\text { the system, applying technological tools that allow the processing of } \\
\text { information on MSW to analyze its management and evaluating } \\
\text { environmental policy. }\end{array}$ \\
\hline S4-City Planning & $\begin{array}{l}\text { The General Directorate for the Coordination of Environmental Policies } \\
\text { and Culture coordinates the Comprehensive Management Program for } \\
\text { MSWs and promotes strategies and mechanisms for the adequate } \\
\text { environmental management of MSWs through reuse, recycling, } \\
\text { and treatment. }\end{array}$ \\
\hline S5-City Board & $\begin{array}{l}\text { The Secretary of the Environment is responsible for applying and } \\
\text { monitoring compliance with the provisions of the local constitution and } \\
\text { the legislation on MSW, regulating and promoting, in coordination with } \\
\text { the Secretariat of Public Works and Services (SOBES), the activities of } \\
\text { minimization, collection, recovery, treatment, recovery of energy, and } \\
\text { disposal of MSW. }\end{array}$ \\
\hline
\end{tabular}




\section{Discussion}

\subsection{Productive Unit}

The primary in-home activity proposed for the adequate incorporation of the IRS MSW in Mexico City is that households separate and store the MSW in four fractions, as indicated by NADF-024-AMBT-2013 [32]. However, since the implementation of NADF024-AMBT-2013, separation efficiency has decreased from 72\% in 2012 to $54 \%$ in 2019 [33]. The Program for the Prevention of Integral Waste Management for Mexico City (PIWM) identifies the lack of compatibility between the working hours of the population and the frequencies and schedules of collection, which causes waste to accumulate and mix in homes or to be abandoned in the streets, as the leading cause of this decrease [33]. The system in Figure 4 proposes that the management of waste storage spaces and frequency of collection services be carried out through neighborhood associations in coordination with the heads of families to avoid these conflicts. At the same time, the monitoring of proper coordination oversees public collection employees.

For these elements to function in harmony, allowing citizen assemblies to propose projects to improve storage in their neighborhoods, supported by the deputies of the city, who approve the budget and legislation on MSW in Mexico City, is suggested.

\subsection{Neighborhood}

In Mexico City, collection is carried out by colonies, and the main problem it faces is low efficiency in the amount of waste collected and its separation. Currently, the public service is responsible for collecting the four fractions into which the MSW is separatedonce a week for non-recyclable and bulky materials and twice a week for recyclable and organic materials-which causes incompatibility in the working hours of the population and the accumulation and mixture of waste in homes, forcing collection workers to separate recyclables in collection trucks. In Figure 5, the proposed model considers the collection of recyclables by the IRS as a primary activity in order to facilitate a greater availability of schedules, avoid the need for the separation of waste, and streamline the process. The cleaning departments of the 16 mayors' offices of the city would manage the collection frequencies of both the drivers of the public service and those of the informal sector. For the monitoring of the collection frequencies, the cleaning departments have cleaning supervisors distributed throughout the city.

To achieve adequate coordination, borough cleaning services are considered in the planning of collection and the modification of collection frequencies according to the requests of the neighborhood associations to include the IRS, with the prior recognition of the policies of the mayors, which will include the informal sector as part of the services coordinated by the cleaning departments.

\subsection{Boroughs}

Regarding the commercialization of waste carried out within the 16 boroughs of the city, no changes were proposed in the functions of this primary activity. The proposed model shown in Figure 6 considers the gathering centers included within the infrastructure for MSW management, coordinated by the direction of transfers and final disposal to ensure coverage according to waste recyclables collected by the IRS. At the same time, the urban service and sustainability directorate manages its operation in conjunction with the treatment and final disposal services. As part of the management of MSW, sustainable solid waste management unit monitoring gathering centers precisely measure the proportion of waste recycled in the city and its destination. The General Directorate of Coordination of Environmental Policies and Culture in charge of the design of the plans and programs for the management of MSW in the city would plan new collection centers [33,42,43], and their inclusion in MSW management is the responsibility of the Ministry of the Environment to apply and monitor compliance with the provisions of the local constitution and legislation on waste. 


\section{Conclusions}

Recycling in most cities in Mexico operates informally, and Mexico City is no exception. The ISR plays a fundamental role in the recycling of MSW, so it is necessary to recognize its participation in public policies and city regulations to improve the living and working conditions of the IRS and increase the collection and recycling efficiency of MSW. However, this does not guarantee its success, and it is crucial to implement control, management, and monitoring instruments to facilitate the formalization process.

This research proposes the use of the Viable System Model, which recognizes the IRS in the recycling of MSW in the different systems, levels, and responsibilities that a complex system such as that of Mexico City has. Environmental waste management efficiency, which is accepted from a social perspective and viable from a financial point of view, can be achieved by including the IRS as the leading actor in the recycling of MSW.

The proposed VSM considers the primary recycling activities and the territory's characteristics (housing, colonies, and boroughs) and indicates those responsible for the coordination, management, monitoring, and planning legislation to ensure its viability with sufficient knowledge of the physical and socioeconomic characteristics of the territory.

In mid-2021, Mexico City introduced the Program for the Integral Management of Waste (PIMW) 2021-2025, in which, for the first time since it was established, the inclusion of the IRS in the management of MSW was proposed. The city government considered an approach based on the creation of cooperatives and microenterprises oriented to the management and recycling of waste. The authorities play a minor role in providing only support through the provision of regulations, equipment, infrastructure, and awarenessraising activities. The city government has set a goal for 2025 to create five microenterprises and cooperatives oriented towards the management and recycling of waste and granting periodic training in each borough to workers and volunteers of cleaning and permanent communication campaigns to recognize their work.

However, the city government has not considered aspects relating to the management of these cooperatives and microenterprises. As explained in the proposed model, it is necessary to identify the primary activities that will be carried out by these cooperatives and microenterprises and those in charge of managing them to ensure their success. This research identifies, based on the current organizational structure, the actors that could be incorporated within their functions for the management of the different activities carried out for the recycling of MSW in Mexico City and the gaps in the current legislation for the recognition and incorporation of the IRS.

A financial evaluation is required to consider the possible implementation of the proposed model, identifying the cost of operating the ISR under the proposed conditions and those that the city government would incur for its management, as well as ensuring its economic viability.

Author Contributions: Conceptualization, F.G.-G. and A.L.C.-P.; methodology, R.T.-P.; formal analysis, F.G.-G. and E.F.G.-H.; data curation, F.G.-G.; writing—original draft preparation, all authors; writing-review and editing, all authors. All authors have read and agreed to the published version of the manuscript.

Funding: This research received no external funding.

Data Availability Statement: Publicly available datasets were analyzed in this study. This data can be found here: https://www.sedema.cdmx.gob.mx/programas/programa/residuos, accessed on 13 March 2020.

Conflicts of Interest: The authors declare no conflict of interest. 


\section{Appendix A}

Table A1. Income from the sale of recyclable materials.

\begin{tabular}{cccc}
\hline Material & Percentage & Ton/Day & \$/Ton \\
\hline Cardboard & $4.0 \%$ & 523.82 & 1800.00 \\
\hline Paper & $5.9 \%$ & 765.58 & 2000.00 \\
\hline Ferrous & $1.2 \%$ & 150.78 & 3450.00 \\
\hline Non-ferrous & $0.3 \%$ & 37.69 & 3555.00 \\
\hline Glass & $2.7 \%$ & 344.45 & 850.00 \\
\hline $\begin{array}{c}\text { Plastics } \\
\text { Recyclables } \\
\text { (Drink bottles) }\end{array}$ & $4.2 \%$ & 547.37 & 4500.00 \\
\hline Total & $18.2 \%$ & 2369.69 & 2483.10 \\
\hline
\end{tabular}

Source: Data from Durán et al. [12], Supraciclaje [44], and Muñoz-Cadena et al. [45].

\section{References}

1. Velis, C.A.; Wilson, D.C.; Rocca, O.; Smith, S.R.; Mavropoulos, A.; Cheeseman, C.R. An analytical framework and tool ('InteRa') for integrating the informal recycling sector in waste and resource management systems in developing countries. Waste Manag. Res. 2012, 30, 43-66. [CrossRef]

2. Wilson, D.C.; Rodic, L.; Scheinberg, A.; Velis, C.A.; Alabaster, G. Comparative analysis of solid waste management in 20 cities. Waste Manag. Res. 2012, 30, 237-254. [CrossRef] [PubMed]

3. Wilson, D.C.; Velis, C.; Cheeseman, C. Role of informal sector recycling in waste management in developing countries. Habitat Int 2006, 30, 797-808. [CrossRef]

4. Mavropoulos, A.; Willson David, C.; Appelqvist, B.; Vells, C.; Cooper, J. Globalization and Waste Management Phase 1: Concepts and Facts; International Solid Waste Association: Vienna, Austria, 2012.

5. Mavropoulos, A. How Industry 4.0 Transforms the Waste Sector; International Solid Waste Association: Rotterdam, The Netherlands, 2019.

6. United Nations World Urbanization Prospects: The 2009 Revision; UN: New York, NY, USA, 2017.

7. INEGI. Cuaderno Estadístico y Geográfico de la Zona Metropolitana del Valle de México 2014, 1st ed.; Instituto Nacional de Estadística y Geografía: Ciudad de México, Mexico, 2014; ISBN 978-607-739-481-5.

8. Guibrunet, L. What is "informal" in informal waste management? Insights from the case of waste collection in the Tepito neighbourhood, Mexico City. Waste Manag. 2019, 86, 13-22. [CrossRef] [PubMed]

9. Secretaría del Medio Ambiente del Gobierno de la Ciudad de México. Inventario de Residuos Sólidos de la Ciudad de México 2019; Secretaría del Medio Ambiente de la Ciudad de México: Ciudad de México, Mexico, 2020.

10. Gutiérrez-Galicia, F.; Coria-Páez, A.L.; Tejeida-Padilla, R. A Study and Factor Identification of Municipal Solid Waste Management in Mexico City. Sustainability 2019, 11, 6305. [CrossRef]

11. Secretaría del Medio Ambiente del Gobierno de la Ciudad de México. Inventario de Residuos Sólidos CDMX 2018; Secretaría del Medio Ambiente de la Ciudad de México: Ciudad de México, Mexico, 2019.

12. Durán, A.; Garcés, M.; Velasco, A.; Marín, J.C.; Gutiérrez, R.; Moreno, A.; Delgadillo, A. Mexico City's municipal solid waste characteristics and composition analysis. Rev. Int. Contam. Ambie 2013, 29, 39-46.

13. Mavropoulos, A. Globalization, Megacities and Waste Management; International Solid Waste Association: Athens, Greece, 2010.

14. Aparcana, S. Approaches to formalization of the informal waste sector into municipal solid waste management systems in lowand middle-income countries: Review of barriers and success factors. Waste Manag. 2017, 61, 593-607. [CrossRef] [PubMed]

15. Wilson, D.C.; Araba, A.O.; Chinwah, K.; Cheeseman, C.R. Building recycling rates through the informal sector. Waste Manag. 2009, 29, 629-635. [CrossRef]

16. Abarca Guerrero, L.; Maas, G.; Hogland, W. Solid waste management challenges for cities in developing countries. Waste Manag. 2013, 33, 220-232. [CrossRef]

17. Gutberlet, J. Informal and Cooperative Recycling as a Poverty Eradication Strategy. Geogr. Compass 2012, 6, 19-34. [CrossRef]

18. Dias, S.M. Overview of the Legal Framework for Inclusion of Informal Recyclers in Solid Waste Management in Brazil. Women in Informal Employment: Globalizing and Organizing. 2011. Available online: https://www.wiego.org/sites/default/files/ publications/files/Dias_WIEGO_PB6.pdf (accessed on 9 November 2021).

19. Terraza, H.; Sturzenegger, G. Dinámicas de organización de los recicladores informales. Tres casos de estudio en América Latina. Sector de infraestructura y medio ambiente. Nota Técnica $N^{\circ} \mathbf{2 0 1 0}, 117,30-42$.

20. Pfammatter, R.; Schertenleib, R. Non-Governmental Refuse Collection in Low-Income Urban Areas: Lessons Learned from Selected Schemes in Asia, Africa and Latin America; Department of Water and Sanitation in Developing Countries: Duebendorf, Switzerland, 1996. 
21. Nas, P.; Jaffe, R. Informal Waste Management. Environ. Dev. Sustain. 2004, 6, 337-353. [CrossRef]

22. Scheinberg, A.; Savain, R. Valuing Informal Integration: Inclusive Recycling in North Africa and the Middle East; Deutsche Gesellschaft für Internationale Zusammenarbeit (GIZ) GmbH: Tunis, Tunisia, 2015.

23. Jackson, M.C. Systems Thinking: Creative Holism for Managers, 1st ed.; J. Wiley: West Sussex, UK, 2003 ; ISBN 9780470845226.

24. Instituto de Estadística y Geografía. Censo Nacional de Gobiernos Municipales y Delegacionales. 2017. Available online: https:/ / www.inegi.org.mx/programas/cngmd/2017/\#Tabulados (accessed on 9 November 2021).

25. Castillo Berthier, H. Garbage, work and society. Resour. Conserv. Recycl. 2003, 39, 193-210. [CrossRef]

26. Guibrunet, L.; Sanzana Calvet, M.; Castán Broto, V. Flows, system boundaries and the politics of urban metabolism: Waste management in Mexico City and Santiago de Chile. Geoforum 2017, 85, 353-367. [CrossRef]

27. Coffey, M.; Coad, A. Collection of MSW in Developing Countries; UN-HABITAT: Tarxien, Malta, 2010; ISBN 978-92-1-132254-5.

28. Couto, I.; Hernández, A. Participación y rendimiento de la iniciativa privada en la gestión integral de los residuos sólidos urbanos en la frontera México-Estados Unidos. Gestión Política Pública 2012, 21, 215-261.

29. Guevara-García, J.A.; Montiel-Corona, V. Pushing Mexico to a recycling culture. In Mexico in Focus; Galindo, J., Ed.; Nova Science Publishers, Inc.: New York, NY, USA, 2015; pp. 141-176. ISBN 978-1-63321-885-7.

30. CNICP. Plan de Manejo Para los Residuos de Papel y Cartón en México; Cámara Nacional de las Industrias de la Celulosa y del Papel: Ciudad de México, Mexico, 2012.

31. Asamblea Legislativa del Distrito Federal. Ley de Residuos Sólidos del Distrito Federal. Gac. Of. del Dist. Fed. 2003, 13, 2-20.

32. Secretaría del Medio Ambiente de la Ciudad de México. Norma ambiental para el distrito federal NADF-024-AMBT-2013, que establece los criterios y especificaciones técnicas bajo los cuales se deberá realizar la separación, clasificación, recolección selectiva y almacenamiento de los residuos del Distrito Feder. Gac. Of. del Dist. Fed. 2015, 18, $22-43$.

33. Jefatura de Gobierno. Programa de Gestión Integral de Residuos para la Ciudad de México 2021-2025. Gac. Ciudad México 2021, $21,4-61$.

34. Jiménez-Martínez, N.M. The governance of waste: Formal and informal rules in the central region of Mexico. Reg. Stud. Reg. Sci. 2018, 5, 353-360. [CrossRef]

35. Espinosa, A.; Harnden, R.; Walker, J. A complexity approach to sustainability-Stafford Beer revisited. Eur. J. Oper. Res. 2008, 187, 636-651. [CrossRef]

36. Ramírez-Gutiérrez, A.G.; Cardoso-Castro, P.P.; Tejeida-Padilla, R. A Methodological Proposal for the Complementarity of the SSM and the VSM for the Analysis of Viability in Organizations. Syst. Pract. Action Res. 2020, 34, 331-357. [CrossRef]

37. Beer, S. The Viable System Model: Its Provenance, Development, Methodology and Pathology. J. Oper. Res. Soc. 1984, $35,7$. [CrossRef]

38. Checkland, P. Soft Systems Methodology: A Thirty Year Retrospective. Syst. Res. Behav. Sci. Syst. Res 2000, 17, 11-58. [CrossRef]

39. Ríos, J.P. Models of organizational cybernetics for diagnosis and design. Kybernetes 2010, 39, 1529-1550. [CrossRef]

40. Núñez-Ríos, J.E.; Aguilar-Gallegos, N.; Sánchez-García, J.Y.; Cardoso-Castro, P.P. Systemic Design for Food Self-Sufficiency in Urban Areas. Sustainability 2020, 12, 7558. [CrossRef]

41. INEGI. Bienvenidos a Cuéntame de México. Instituto Nacional de Geografía y Estadística. 2015. Available online: http:/ / cuentame. inegi.org.mx/ (accessed on 9 November 2021).

42. Secretaría del Medio Ambiente de la Ciudad de México. PGIRS 2016-2020; Secretaría del Medio Ambiente de la Ciudad de México: Ciudad de México, Mexico, 2016.

43. Secretaría del Medio Ambiente de la Ciudad de México. Programa de Gestión Integral de los Residuos Sólidos para el Distrito Federal 2009-2014. Gac. Dist. Fed. 2009, 17, 25-133.

44. Supraciclaje Precios Hoy. Supraciclaje. 2020. Available online: https://www.supraciclaje.com/precios-hoy/ (accessed on 13 March 2020).

45. Muñoz-Cadena, C.E.; Arenas-Huertero, F.J.; Ramón-Gallegos, E. Comparative analysis of the street generation of inorganic urban solid waste (IUSW) in two neighborhoods of Mexico City. Waste Manag. 2009, 29, 1167-1175. [CrossRef] 